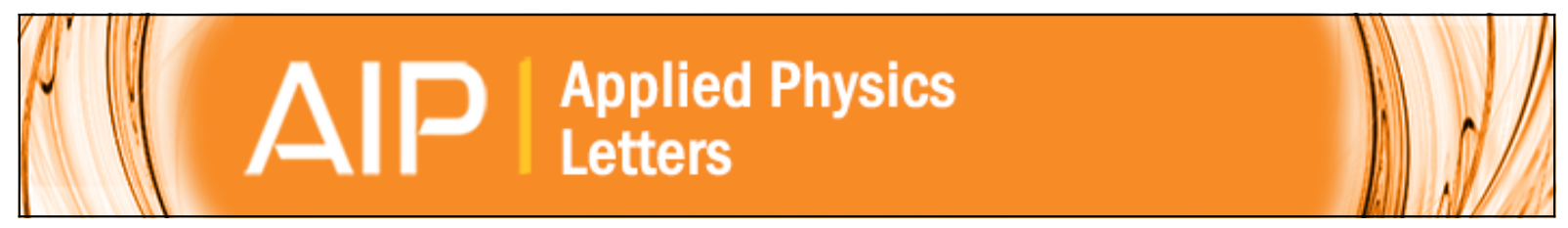

\title{
Bias-enhanced nucleation of highly oriented diamond on titanium carbide (111) substrates
}

S. D. Wolter, M. T. McClure, J. T. Glass, and B. R. Stoner

Citation: Applied Physics Letters 66, 2810 (1995); doi: 10.1063/1.113483

View online: http://dx.doi.org/10.1063/1.113483

View Table of Contents: http://scitation.aip.org/content/aip/journal/apl/66/21?ver=pdfcov

Published by the AIP Publishing

\section{Articles you may be interested in}

Highly oriented perpendicular Co-alloy media on $\mathrm{Si}(111)$ substrates

J. Appl. Phys. 85, 4699 (1999); 10.1063/1.370452

Ellipsometric monitoring of an oriented diamond nucleation process in bias-enhanced chemical vapor deposition Appl. Phys. Lett. 71, 2913 (1997); 10.1063/1.120214

Bias-enhanced nucleation of diamond on silicon dioxide

Appl. Phys. Lett. 71, 716 (1997); 10.1063/1.119839

Mechanism of bias-enhanced nucleation of diamond on $\mathrm{Si}$

Appl. Phys. Lett. 66, 3287 (1995); 10.1063/1.113732

Evidence of an energetic ion bombardment mechanism for bias-enhanced nucleation of diamond Appl. Phys. Lett. 66, 3117 (1995); 10.1063/1.113621

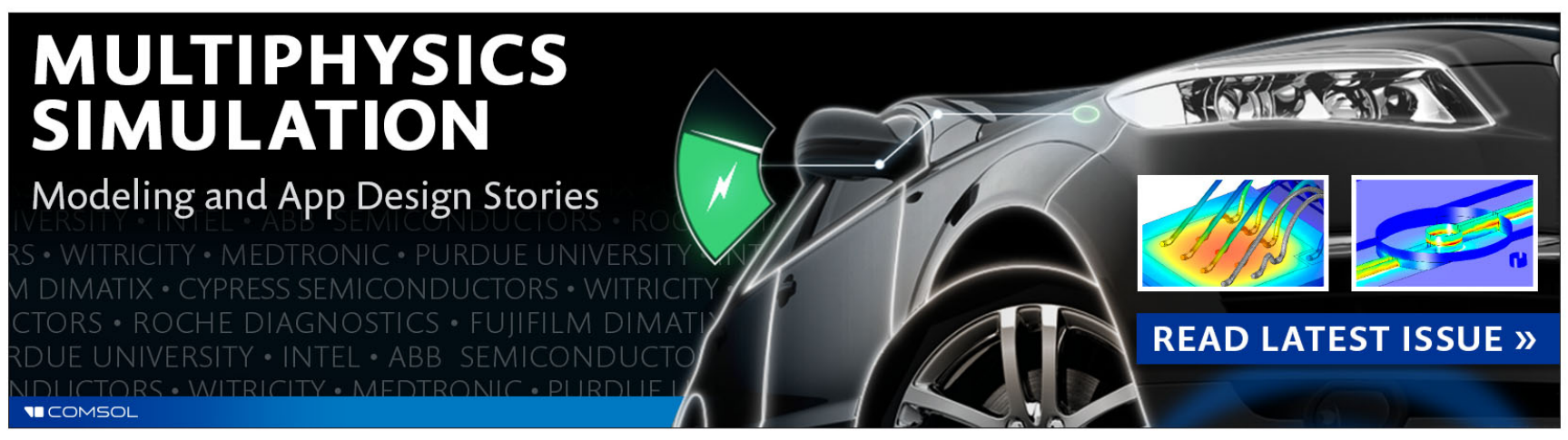




\title{
Bias-enhanced nucleation of highly oriented diamond on titanium carbide (111) substrates
}

\author{
S. D. Wolter, ${ }^{\text {a) }}$ M. T. McClure, ${ }^{\text {a),b) }}$ and J. T. Glass ${ }^{\text {() }}$ \\ Department of Materials Science and Engineering, North Carolina State University, \\ Raleigh, North Carolina 27695-7919
}

B. R. Stoner

Electronic Materials Research Center, Kobe Steel USA Inc., Research Triangle Park, North Carolina 27709

(Received 27 February 1995; accepted for publication 23 March 1995)

\begin{abstract}
The bias-enhanced nucleation (BEN) technique has been applied to $\mathrm{TiC}(111)$ substrates and resulted in deposition of oriented diamond particles. The orientation was observed via scanning electron microscopy. A dense region of oriented particles was not observed on the samples, presumably due to the excessive twinning of the diamond. However, micrographs taken throughout the substrate showed diamond particles having similar orientation with respect to each other. Some of the diamond particles showed evidence of azimuthal twist and tilting, resulting most likely from the $\sim 21 \%$ lattice mismatch. Raman spectra of the diamond crystals show a strong feature at 1332 $\mathrm{cm}^{-1}$, which is indicative of diamond, and smaller features at 1480 and $1602 \mathrm{~cm}^{-1}$ due to $s p^{2}$-bonded carbon. (C) 1995 American Institute of Physics.
\end{abstract}

Diamond has received much attention for use in a wide variety of applications. These include tribological, thermal management, optical, and microelectronic applications. In order to exploit this material's extreme properties, high quality diamond crystals must be formed and in some cases, through process advancements, the properties of synthetic diamond have surpassed those exhibited by natural diamond. ${ }^{1}$ To make full use of diamond's electronic properties single-crystal films devoid of electronic barriers posed by grain boundaries and randomly oriented crystals are required. Thus, the need to identify alternative heteroepitaxial substrates for diamond is important.

Epitaxial diamond films have been grown on both $c-\mathrm{BN}$ and diamond, ${ }^{2-4}$ however, these materials are expensive and large area substrates are not available. There has been past research to suggest that diamond heteroepitaxy may be achieved on other nondiamond or related substrates, and the recent deposition on $\beta$-SiC, $\mathrm{Si}$, and $\mathrm{Ni}$ have shown the most dramatic results. ${ }^{5-11}$ In the case of the work conducted on $\beta$-SiC and $\mathrm{Si}$, bias-enhanced nucleation (BEN) was used for the formation of these epitaxial diamond crystals. ${ }^{12}$ The term highly oriented diamond (HOD) has been used to describe the partial alignment of individual grains. The individual particles may be epitaxial with respect to the substrate, however tilting in both azimuthal and transverse directions results in the formation of low-angle grain boundaries. ${ }^{13}$ The origin of this misalignment is believed to be a result of an $\sim 22 \%$ mismatch at the diamond/SiC interface. ${ }^{10}$

It has been revealed through continued research that the success of BEN as a nucleation enhancement technique is related to the carbide forming nature of the substrate is com-

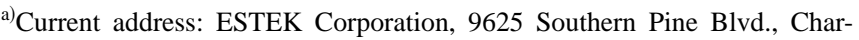
lotte, NC 28273.

b)Electronic mail: mcclure@amte.ncsu.edu.

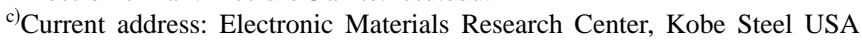
Inc., Research Triangle Park, NC 27709.
}

mensurate with the effective utilization of this nucleation pretreatment process. A study of several refractory metal substrates by Wolter et al. ${ }^{14}$ indicated that a correlation was observed between both the time before the onset of significant diamond nucleation, and the diamond nucleation density to the heat of carbide formation of the substrate. That study revealed titanium had a diamond nucleation density $\left(10^{9} \mathrm{~cm}^{-2}\right)$ approximately one order of magnitude less than silicon and would be a likely candidate for further heteroepitaxy studies using BEN. In general, the refractory metals are similar to silicon in the respect that they are known carbide formers, but they are quite different in other respects. One of these differences is that the $\mathrm{TiC}(111)$ like the other refractory monocarbides possess a different crystal structure to that of $\mathrm{SiC}$ (TiC-rock salt structure; SiC-zinc blende structure). This letter discusses BEN on single-crystal TiC(111) substrates.

Similar experimental conditions to the work performed by Stoner et al. ${ }^{5}$ on $\beta$-SiC has been utilized on $\mathrm{TiC}(111)$ to investigate the possibility of obtaining diamond heteroepitaxy when using BEN. The samples used were $\mathrm{TiC}(111)$ single-crystal substrates from Advanced Technology and Materials, Inc. The samples were polished to $30,6,1$, and 0.1 $\mu \mathrm{m}$ diamond grit followed by $1 \mathrm{~h}$ of polishing using $0.05 \mu \mathrm{m}$ $\mathrm{Al}_{2} \mathrm{O}_{3}$ to remove any residual diamond that may have been embedded in the TiC surface. After polishing, the samples were cleaned using acetone, methanol, and isopropanol. The

TABLE I. MPCVD system parameters for each process.

\begin{tabular}{lccc}
\hline \hline System parameter & $\mathrm{H}_{2}$ plasma clean & BEN & Growth \\
\hline Power $(\mathrm{W})$ & 600 & 600 & 600 \\
Pressure (Torr) & 25 & 15 & 40 \\
$\mathrm{CH}_{4}: \mathrm{H}_{2}$ ratio & $\ldots$ & $5 \%$ & $0.2 \%$ \\
Bias current $(\mathrm{mA})$ & $\ldots$ & 120 & $\ldots$ \\
Bias voltage $(\mathrm{V} \mathrm{dc})$ & $\ldots$ & $225 \pm 10$ & $\ldots$ \\
Temperature $\left({ }^{\circ} \mathrm{C}\right)$ & $660 \pm 20$ & $785 \pm 20$ & 900 \\
Duration & $30 \mathrm{~min}$ & $10-15 \mathrm{~min}$ & $8 \mathrm{~h}$ \\
\hline \hline
\end{tabular}




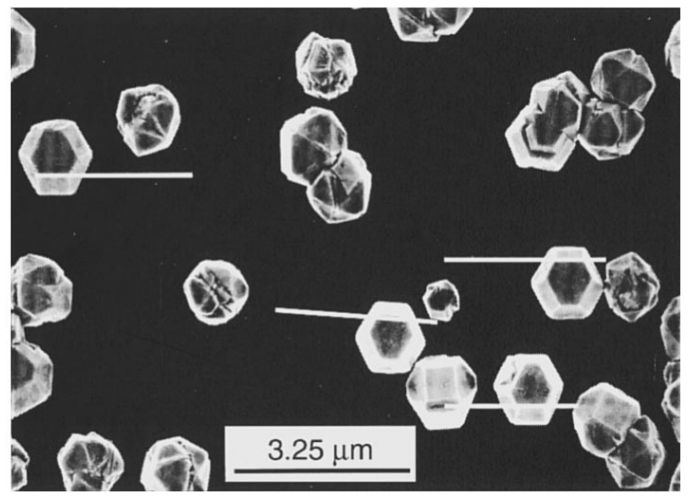

FIG. 1. SEM micrograph of oriented diamond particles on TiC(111) substrate. The marker is $3.75 \mu \mathrm{m}$ in length. The lines show the common direction of the diamond particles.

samples were then cleaned in a $\mathrm{H}_{2}$ plasma for 30 min to remove any oxide present on the surface followed by the BEN process for 10-15 min depending on the sample. The specific system parameters for each stage of the diamond deposition are listed in Table I. The deposition system used was an ASTeX $2.45 \mathrm{MHz} 1.5 \mathrm{~kW}$ system that has been described in detail elsewhere. ${ }^{15,16}$

The diamond deposition was observed and characterized by scanning electron microscopy (SEM) and by Raman spectroscopy. Figure 1 shows a micrograph of diamond particles oriented with each other along the $\langle 110\rangle$ directions and micrographs taken throughout the substrate showed diamond particles having the same orientation. Since these particles were oriented with each other across the substrate and to etch pits observed in the substrate surface, the particles are assumed to be highly oriented to the substrate. Figure 2 shows other oriented diamond particles and a representation of the substrate orientation, determined by pits seen on the TiC surface. The diamond particle density was $1.5 \times 10^{8} \mathrm{~cm}^{-2}$ and the percentage of particles oriented to each other ranged from $10 \%-15 \%$ across the substrate.

A short BEN duration, resulting in a moderate to low nucleation density, was chosen to allow observation of diamond particles separated from one another and to prevent coalescence into a complete film. This also avoided delamination of the films expected from the differences in the coefficients of thermal expansion between diamond and TiC.

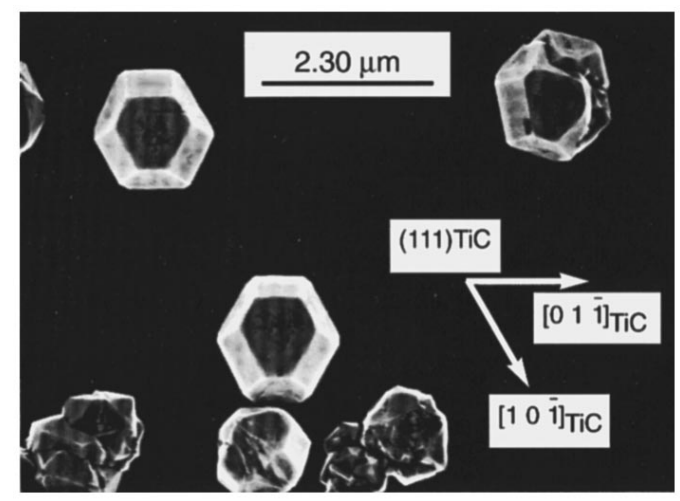

FIG. 2. SEM micrograph of oriented diamond particles with arrows depicting the $\mathrm{TiC}(111)$ substrate orientation. The marker is $2.30 \mu \mathrm{m}$ in length.

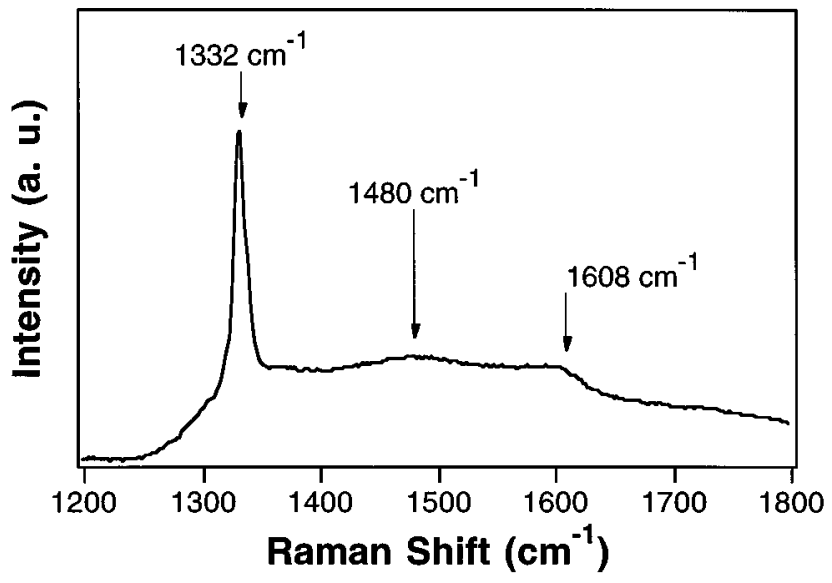

FIG. 3. Micro-Raman spectrum of the diamond particles on the TiC(111) substrate. The spectrum shows a sharp peak at $1332 \mathrm{~cm}^{-1}$ characteristic of diamond and the features at 1480 and $1602 \mathrm{~cm}^{-1}$ are characteristic of $s p^{2}$-bonded carbon.

However, the growth conditions were not optimized for suppressing twinning on the (111) face which may have disguised a higher percentage of particles that were initially oriented. Improvement of the growth conditions and attempted nucleation on alternative faces of $\mathrm{TiC}$ should further increase the percentage of oriented particles and will be the subject of future development.

Raman spectroscopy of the diamond particles is shown in Fig. 3. The characteristic diamond feature at $1332 \mathrm{~cm}^{-1}$ is present and the features at 1480 and $1602 \mathrm{~cm}^{-1}$ are indicative of $s p^{2}$-bonded carbon. The inordinate number of twinned particles on the surface may account for most of the $s p^{2}$ features seen in the Raman spectrum.

Bias enhanced nucleation of diamond has produced highly oriented diamond particles on $\mathrm{TiC}(111)$ substrates despite a $21 \%$ lattice mismatch. Optimization of the growth conditions or growth on other faces of $\mathrm{TiC}$ should increase the density of oriented particles. Further analysis of the $\mathrm{TiC} /$ diamond interface should provide more information for the heteroepitaxial deposition of diamond on other substrates.

The authors wish to thank Dr. D. Brown at Advanced Technologies and Materials, Inc. for supplying the substrates. This work was funded in part by the Ballistic Missile Defense Organization/Innovative Science and Technology Program through the Office of Naval Research.

${ }^{1}$ T. R. Anthony, W. F. Banholzer, J. F. Fleischer, L. Wei, P. K. Kuo, R. L. Thomas, and R. W. Pryor, Phys. Rev. B 42, 1104 (1990).

${ }^{2}$ H. Meada, S. Masuda, K. Kusakabe, and S. Morooka, Diam. Relat. Mater. 3, 398 (1994).

${ }^{3}$ S. Koizumi, T. Murakami, T. Inuzuka, and K. Suzuki, Appl. Phys. Lett. 57, 563 (1990).

${ }^{4}$ M. Kamo, H. Yurimoto, and Y. Sato (ICSFS-4) 33-34, 553 (1988).

${ }^{5}$ B. R. Stoner, G. H. Ma, S. D. Wolter, W. Zhu, Y.-C. Wang, R. F. Davis, and J. T. Glass, Diam. Relat. Mater. 2, 142 (1993).

${ }^{6}$ B. R. Stoner, Ph.D. thesis, North Carolina State University, 1992.

${ }^{7}$ P. C. Yang, W. Zhu, and J. T. Glass, J. Mater. Res. 8, 1773 (1993).

${ }^{8}$ S. D. Wolter, B. R. Stoner, J. T. Glass, P. J. Ellis, D. S. Buhaenko, C. E. Jenkins, and P. Southworth, Appl. Phys. Lett. 62, 1215 (1993). 
${ }^{9}$ Y. Sato, I. Yashima, H. Fujita, T. Ando, and M. Kamo, in Proceedings of New Diamond Science and Technology, Washington, D.C., September 2327, 1990, edited by R. Messier, J. T. Glass, J. E. Bulter, and R. Roy (Materials Research Society, Pittsburgh, PA), p. 371.

${ }^{10}$ X. Jiang, C.-P. Klages, R. Zachai, M. Hartweg, and H.-J. Füsser, Appl. Phys. Lett. 62, 3438 (1993).

${ }^{11}$ C. Wild, R. Kohl, N. Herres, W. Müller-Sebert, and P. Koidl, Diam. Relat. Mater. 3, 373 (1994).
${ }^{12}$ B. R. Stoner and J. T. Glass, Appl. Phys. Lett. 60, 698 (1971)

${ }^{13}$ W. Zhu, X. H. Wang, B. R. Stoner, G. H. M. Ma, H. S. Kong, M. W. H. Braun, and J. T. Glass, Phys. Rev. B 47, 6529 (1993).

${ }^{14}$ S. D. Wolter, J. T. Glass, and B. R. Stoner, J. Appl. Phys. (to be published).

${ }^{15}$ K. L. Merkle and D. J. Smith, Ultramicroscopy 22, 57 (1987).

${ }^{16}$ H. Hashimoto, Y. Takai, Y. Yokota, H. Endoh, and E. Fukada, Jpn. J. Appl. Phys. Lett. 19, 1 (1980). 